\title{
Plenos de CIRCUITO EN MÉxico: ¿ÓRganos EFICACES PARA LA CONSTRUCCIÓN DEL CRITERIO JURISDICCIONAL REGIONAL?
}

\section{Alma Elizabeth Hernández López ${ }^{1}$}

RESUMEN: Este documento contiene un breve análisis sobre los Plenos de Circuito, su establecimiento, naturaleza y primordialmente, a la luz de la problemática que en lo fáctico constituye su funcionamiento, el escrutinio de su eficacia para construir la doctrina jurisdiccional regional, el precedente uniforme y relevante que dote de seguridad y sentido al sistema jurídico.

Palabras clave: Plenos de Circuito, Tribunal Colegiado, contradicción de tesis, Suprema Corte de Fusticia de la Nación, jurisprudencia.

ABSTRACT: This document contains a brief analysis on the Plenary Circuits, its establishment, nature and primarily, in light of the problems that actually constitute its operation, the scrutiny of its effectiveness to build the regional jurisdictional doctrine, the uniform precedent and relevant that provides security and meaning to the legal system.

Keywords: Plenary Circuit, Collegiate Court, contradiction of thesis, Supreme Court of Justice of the Nation, jurisprudence

Sumario: I. Nota introductoria. II. ¿Qué son los Plenos de Circuito? III. Sobre su organización. IV. Problemática. VI. Reflexiones finales y aportaciones. VI. Fuentes de Consulta

1 Secretaria de Estudio y Cuenta del Primer Tribunal Colegiado en Materia Civil del Tercer Circuito. 
"El árbol de las leyes ha de podarse continuamente."

\section{NOTA INTRODUCTORIA}

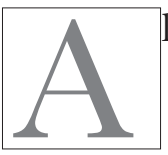

1 inaugurarse los Plenos de Circuito, el entonces ministro presidente de la Suprema Corte de Justicia de la Nación sostuvo que se caracterizarían por su profesionalismo, objetividad, imparcialidad e independencia, participando en la construcción colectiva de la doctrina jurisdiccional, ${ }^{2}$ a cinco años de aquellas palabras, estos órganos han tenido que enfrentarse a situaciones fácticas que los alejan de realizar de forma efectiva los fines para los cuales fueron creados, merece entonces analizar de que van estos órganos, valorar su realidad y por supuesto proponer alternativas en aras de su eficacia como interpretes últimos de la norma local.

\section{II. ¿QUÉ SON LOS PLENOS DE CIRCUITO?}

\section{Fundamento desde la constitución}

Los Plenos de Circuito (en lo subsecuente PG) fueron parte de la reforma de la Constitución Federal de seis de junio de dos mil once, en los párrafos séptimo y décimo del artículo 94 y la fracción XIII del numeral 107, se impuso el deber del Consejo de la Judicatura Federal de regular, mediante acuerdos generales, su establecimiento, integración y funcionamiento, en tanto que la Ley de Amparo fijaría los términos de obligatoriedad de la jurisprudencia, así como los requisitos para su interrupción y sustitución, también se definió de forma general la competencia de estos órganos para resolver las

2 Rodríguez, Magally, "Los Plenos de Circuito deberán respetar, por encima de todo, los derechos humanos: Ministro Silva Meza", Compromiso, Órgano informativo del Poder Judicial de la Federación, México, Junio 2013, año 12/No. 144- junio de 2013, p.3. 
contradicciones de tesis suscitadas entre los Tribunales Colegiados de un mismo Circuito (enseguida TG), la legitimación para hacer la denuncia relativa y el supuesto de solución de controversias entre PG - ya del mismo circuito y diversa materia o de distinto circuitoentre éstos y Tribunales Colegiados con diferente especialización.

A partir de entonces se tuvo que lidiar con la falta de instrumentación de esta figura desconocida inclusive para sus operadores - hasta la fecha para gran parte del foro jurídico- por ello, la Suprema Corte asumió el conocimiento de los asuntos cuya competencia correspondía a estos entes, con el voto disidente y reiterado de uno de sus integrantes, ${ }^{3}$ esta situación no fue del todo fugaz, el comienzo de los PG debió esperar para materializarse más de un año, fue hasta junio de dos mil trece, a través de una videoconferencia trasmitida simultáneamente a nivel nacional y presidida por el entonces Ministro Juan Silva Meza, ${ }^{4}$ que se puso en marcha y dio inicio el funcionamiento de 34 Plenos de Circuito. ${ }^{5}$

\section{2. ¿Origen gaucho de los Plenos de Circuito?}

Puede afirmarse que los PC, tal como se instituyeron en México, no tienen un antecedente exacto importado de otro lugar sin embargo, existen sistemas de unificación de jurisprudencia en varias

3 El Ministro José Ramón Cossío Díaz formuló voto señalando substancialmente: "Actualmente no existe en el sistema jurídico mexicano ninguna norma que otorgue un poder público a la Suprema Corte de Justicia de la Nación para que dirima contradicciones de tesis provenientes de tribunales colegiados de diferente circuito. Tal supuesto fue suprimido mediante el decreto de reforma constitucional publicado el seis de junio de dos mil once en el Diario Oficial de la Federación". Voto particular del citado Ministro en la contradicción de tesis $281 / 2011$.

4 Rodríguez, Magally, "Los Plenos de Circuito deberán respetar, por encima de todo, los derechos humanos: Ministro Silva Meza"...Ibidem, pp. 4 a 7.

5 En la actualidad son 53 Plenos, de acuerdo con la información que se publica en la página electrónica: www.cjf.gob.mx/plenoscircuito.htm. 
partes del mundo que tienen rasgos similares y también diferencias que pueden ser útiles para determinar las modificaciones necesarias para la completa eficacia de estos órganos, me referiré en particular al caso de Argentina por ser un precedente cercano que además tiene coincidencias importantes que permiten considerar que se dio un viso a la organización de aquel lugar.

En ese país son dos los sistemas para uniformar la jurisprudencia entre tribunales colegiados o cámaras de apelaciones, ${ }^{6}$ el primero, consistente en un órgano superior encargado de decidir el criterio imperante y con carácter obligatorio para los inferiores, a través de Cámaras ad hoc - como la Cámara Nacional de Casación Penal-o la Suprema Corte de Justicia en su calidad de ente superior que está investida con dos tipos de competencia de alzada, una ordinaria de apelación y otra "extraordinaria" a través de la cual puede asegurar la uniformidad de la interpretación constitucional; ${ }^{7}$ en el segundo mecanismo, la misma cámara de apelación, dividida en salas, es la que unifica los criterios divergentes entre ellas, o los surgidos entre cámaras de diversos distritos, tal es el caso de la provincia de Santa Fe, en donde la resolución adoptada por la totalidad de las cámaras de las cinco circunscripciones judiciales recibe el nombre de "fallo plenario".

En Buenos Aires este mecanismo se concreta a través de una reunión plenaria por autoconvocatoria o a petición de parte, ${ }^{8}$ de acuerdo con el artículo 37 de la Ley Provincial 5.827 Ley Orgánica

6 Leguisamón, Eduardo. Unificación de la jurisprudencia. Copyright 2013, elDial.com - editorial albrematica - Tucumán 1440 (1050) - Ciudad Autónoma de Buenos Aires - Argentina, publicado el 27/05/2013, <https://agendamagna. wordpress.com/2013/05/26/unificacion-de-la-jurisprudencia/>.

7 Brewer-Carías Allan R., El Proceso de Amparo en el Derecho Constitucional Comparado de América Latina, México, Porrúa, 2016, p.179.

${ }^{8}$ Con la ley 26.853 en vigor a partir del 20 de mayo de 2013, desapareció el recurso de inaplicabilidad de la ley, la autoconvocatoria y la obligatoriedad de los fallos plenarios. 
del Poder Judicial; ${ }^{9}$ la sentencia define el criterio aplicable a casos análogos y cuando la iniciativa se realiza antes de que se resuelva el caso concreto, el mismo se falla de conformidad con el mismo. ${ }^{10}$

La regulación bonaerense, al igual que la mexicana, prevé la solución de contradicciones de criterios suscitados en una circunscripción determinada ante los órganos que la integran, también el criterio fijado se establece como obligatorio, sin embargo, una diferencia interesante es que la denuncia de contradicción puede acontecer antes de la solución del caso concreto cuando el tribunal resolutor advierte la divergencia de criterios, aspecto que tiene la bondad de otorgar una respuesta congruente con la tesis que será obligatoria; en nuestro país, la resolución que decida la contradicción de tesis siempre surge frente a asuntos fallados, inclusive existe disposición en el sentido de que la resolución de contradicción no afecta las situaciones jurídicas concretas de los juicios en los cuales se hayan dictado las sentencias que sustentaron las tesis contradictorias. ${ }^{11}$ Para evitar la existencia de soluciones distintas a casos iguales -actuación que algunos atribuyen a la ignorancia e incapacidad de los Magistrados de los $\mathrm{TC}^{-12}$ válidamente podría proponerse que en los asuntos en los que el propio TC advierta que existe divergencia

9 Artículo 37: Cuando un mismo caso Judicial haya sido objeto de resoluciones divergentes por parte de distintas Cámaras o de distintas Salas de una misma Cámara de un Departamento Judicial, al presentarse posteriormente uno similar, será resuelto por las Cámaras del mismo fuero o la Cámara en pleno respectivamente, de acuerdo con las siguientes reglas: (...) Sin perjuicio de las disposiciones que sobre el recurso de inaplicabilidad de ley contiene la Constitución, la interpretación de las normas legales será obligatoria para las Salas de la misma Cámara y Jueces del Departamento Judicial". Tomado de la página web del Ministerio de Gobierno de Buenos Aires, Argentina: <http://www.gob.gba.gov.ar/legislacion/ legislacion/l-5827.html>.

10 Leguisamón, Eduardo. Unificación de la jurisprudencia... Op. cit., p 6.

11 Ley de Amparo, artículo 226.

12 Chávez Castillo Raúl, La nueva Ley de Amparo comentada, 6a. ed. México, Porrúa, 2014, pp. 672 a 675. 
de criterios, previo a resolver el caso en particular, el PC determine cuál es criterio obligatorio favoreciendo así la resolución de forma congruente con la jurisprudencia obligatoria, sin que se transgreda la cosa juzgada respecto de los procedimientos en los que existe sentencia y sin perder de vista el costo en tiempo que esto implica, pues de esperar la resolución del PC, sería mayor el beneficio obtenido al evitar que exista un asunto en el que se aplique un criterio sujeto a controversia provocando que en asuntos idénticos, "en uno se gane y en el otro se pierda". ${ }^{13}$

\section{Naturaleza y fines}

Se ha dicho ya que los PG no tienen precedente, tampoco existe una definición legal y por su parte la doctrina poco se ha ocupado de ellos -en algunos casos se establece su necesaria existencia ${ }^{14}$ y otros

13 “En México es posible generar jurisprudencia por contradicción de tesis! Es decir, ¡dos o más asuntos idénticos o similares se resuelven cada uno con su respectiva justicia! ¡Que excelente sistema de impartición de justicia! En los mismos o idénticos asuntos, junos gobernados ganan y otros pierden el juicio de amparo![...]”. Alvarado Esquivel, Miguel de Jesús, "La jurisprudencia por resolución de contradicciones de tesis de la nueva Ley de Amparo. Criticas para su eliminación”, en Ferrer Mac-Gregor, Eduardo y Herrera García, Alfonso (coords.) El fuicio de Amparo en el centenario de la Constitución Mexicana de 1917 pasado, presente y futuro t. II, México, Universidad Nacional Autónoma de México, Instituto de Investigaciones Jurídicas, 2017, p.489.

14 "Las reformas constitucionales de 1994 no fueron suficientemente meditadas, pues si bien es cierto otorgaron a nuestro más Alto Tribunal mayores funciones materiales de un Tribunal Constitucional (que ya tenía desde la reforma constitucional de 1987), se olvidó de la necesidad de establecer un órgano equivalente a un tribunal supremo o sala superior federal que tuvieran las atribuciones esenciales de unificar la jurisprudencia de legalidad y la facultad de atracción para los asuntos de gran trascendencia, pues dichas facultades no corresponden a un Tribunal Constitucional en sentido propio. En ese sentido es necesario meditar una solución para el futuro que al mismo tiempo que refuerce y vigorice las atribuciones de la Suprema Corte como organismo jurisdiccional especializado en la solución de conflictos constitucionales". Ferrer Mac-Gregor, Eduardo, Panorámica 
se consideran como una innovación de poca pinta- ${ }^{-15}$ sin embargo, pueden establecerse como elementos esenciales que los conforman y permiten su comprensión, los siguientes:

a) Se trata de un órgano del Poder Judicial de la Federación que figura en el organigrama de la institución -o debería hacerlo- distinto a los tribunales cuyos titulares lo constituyen;

b) Integrado por Magistrados de Tribunales Colegiados, ya sea de una materia específica o mixtos;

c) Su función es fijar el criterio jurisdiccional imperante en un circuito y en su caso, materia, en un tiempo determinado, a través de la resolución de contradicciones de tesis suscitadas entre Tribunales de la propia materia y circuito.

d) Son órganos competentes para emitir jurisprudencia obligatoria en los términos que fija la Ley de Amparo; la obligatoriedad de tal jurisprudencia se circunscribe a los órganos inferiores que residan dentro del circuito en que ejerza jurisdicción el Pleno de Circuito respectivo y no para aquellos que sean ajenos a éste, ${ }^{16}$ tampoco para los otros $\mathrm{PG}$, inclusive aquellos de diversa materia del propio circuito. ${ }^{17}$

del Derecho procesal constitucional y convencional, 2da. reimp. México, Universidad Nacional Autónoma de México Instituto de Investigaciones Jurídicas Marcial Pons, 2017, p. 217

15 Ferrer Mac.Gregor, Eduardo y Sánchez Gil, Rubén, El Nuevo Juicio de Amparo. Guía de la reforma constitucional y la nueva Ley de Amparo, 4ta ed, México, Porrúa, 2013, p.238.

16 Chávez Castillo Raúl, La nueva Ley de Amparo comentada, 6a. ed. México, Porrúa, 2014, p. 672.

17 Bravo Peralta, Martín Virgilio, Método del caso jurisprudencial interpretación, argumentación y jurisprudencia, $2^{\mathrm{a}}$. reimp., Ciudad de México, Porrúa, 2016, p. 85. 
e) Con atribuciones para efectuar la solicitud de sustitución de jurisprudencia y la declaratoria general de inconstitucionalidad de una norma, relevantes para la conformación del criterio regional.

Podría concluirse que el PG es un órgano del Poder Judicial de la Federación, integrado por Magistrados de Tribunales Colegiados, cuya función es fijar el criterio jurisdiccional imperante en un circuito y en su caso, materia, en un tiempo determinado, a través de la resolución de contradicciones de tesis suscitadas entre tribunales de la propia materia y circuito, de donde deriva jurisprudencia obligatoria, con atribuciones para efectuar la solicitud de sustitución de jurisprudencia y la declaratoria general de inconstitucionalidad de una norma.

En cuanto a sus fines, el Dictamen de las Comisiones Unidas de Puntos Constitucionales y de Estudios Legislativos del Senado, relativo a la reforma constitucional en comento, justifica la creación de los PG en tres aspectos: ${ }^{18}$

a) Fortalecimiento de la Suprema Corte de Justicia de la Nación como órgano de control constitucional, a través de la despresurización de trabajo, permitiéndole abocarse al conocimiento de asuntos de mayor relevancia respecto de los cuales mantiene la competencia exclusiva;

b) Reconocimiento de los Magistrados de los Tribunales Colegiados, como conformadores efectivos de criterios de interpretación, pues son quienes conocen con mayor proximidad la problemática del circuito y cuentan con experiencia para darle solución a éstas;

18 Sosa Ortiz, Alejandro, La jurisprudencia en la nueva ley de amparo. $2^{\mathrm{a}}$ ed, México, Porrúa, 2017, p. 28. 
c) Dotar de "autonomía" a los circuitos judiciales. Expresamente se señaló: "Se propone la reforma a los artículos 94, 100 y 107 constitucionales por virtud de la cual se les otorga a los actuales circuitos judiciales una autonomía relativa que permitirá darles mayor homogeneidad, precisión y especificidad a los criterios y precedentes que se generen en ese Circuito, sin necesariamente extender al resto de los mismos". ${ }^{19}$ Ahora me limitaré a señalar que esa "autonomía relativa” solo se refiere al ámbito territorial de competencia de los PG, porque administrativamente no cuentan con un presupuesto, ni con recursos materiales o de personal propio y en torno al ejercicio interpretativo que realizan, como enseguida se verá, en muchas ocasiones descansa en las resoluciones que emite la Suprema Corte de Justicia.

Podría agregarse dos razones más:

d) Celeridad en la resolución de las contradicciones de tesis, pues como es sabido la Suprema Corte puede tardar en resolver -inclusive años- en virtud del cumulo y complejidad de asuntos de su competencia, pero además, porque carece de un término para pronunciarse, delimitación con la que si cuentan los PG-actualmente tienen 15 días para proponer proyecto de resolución-20 y en ese sentido su creación si colma tal finalidad, aunque existen practicas cuestionables al respecto, que más adelante se exponen

e) Mayor especialización en la conformación del criterio regional, esto atiende básicamente a que son los ma-

19 Ibidem, p. 27.

20 Conforme al artículo 28 del Acuerdo General 8/2015 del Pleno del Consejo de la Judicatura Federal. 
gistrados que integran los TC de determinado circuito judicial los expertos en la normativa y la problemática local, de manera que resulta más probable que la solución propuesta se ajuste a las necesidades fácticas que imperan en el circuito.

\section{REgulación}

El grueso de la normativa de los PC es obra del Consejo de la Judicatura Federal a través de su facultad reglamentaria, fuera de ello tenemos los mencionados artículos 94 y 107, fracción XII constitucionales, como base estructural, que solo determinan su creación de forma muy genérica; en el título tercero bis de la Ley Orgánica del Poder Judicial Federal encontramos tres capítulos que regulan su integración y funcionamiento, sus atribuciones y la reglamentación sobre su presidente, en tanto que la Ley de Amparo dispone la obligatoriedad de la jurisprudencia que emiten, ésto, en los artículos 216, 217, 218, 219, 225, 226 у 227.

En cuanto a la reglamentación, a partir de fueron creados los PC se han emitido las siguientes disposiciones:

Respecto del funcionamiento orgánico de los Plenos de Circuito:

* Acuerdo General 14/2013, derogado.

* Acuerdo General 11/2014, derogado.

* Acuerdo General 8/2015 del Pleno del Consejo de la Judicatura Federal, relativo a la integración y funcionamiento de los PC. Constituye la normativa en vigor más especializada sobre los órganos en estudio cuyos precedentes son los mencionados acuerdos 14/2013 y 11/2014 derogados, se integra de 56 artículos y 5 transitorios en los que se norma su integración, funcionamiento, lo relativo a las sesiones, el quórum, asistencia, orden del día, votación - aspecto relevante para este artículo que se analizará con más detalle- los asuntos de 
los que conoce, el sistema electrónico al cual ya se ha hecho referencia, la facultad para solicitar la declaratoria general de inconstitucionalidad, la elaboración de tesis y publicación de tesis, los libros electrónicos - objeto de estudio en las visitas de inspección - y por último, pero no menos trascendente, la facultad del Pleno y las Comisiones de Creación de Nuevos Órganos y de Administración del Consejo de la Judicatura Federal para interpretar y resolver cualquier controversia que se suscite con motivo de la aplicación del acuerdo.

* Acuerdo General 52/2015 CJF que reforma, adiciona y deroga disposiciones del similar 8/2015, relativo a la integración y funcionamiento de los PC. Conformado por artículo único u dos transitorios, constituye en realidad un adendum del acuerdo mencionado en el párrafo anterior, pues reforma, deroga, y adiciona algunos de sus artículos. ${ }^{21}$

En cuanto al Sistema electrónico de los PC:

* Manual de usuario del Sistema de Plenos de Circuito, se trata de un documento creado exprofeso para el manejo del sistema electrónico de PC que permite dar seguimiento al proceso de trámite y resolución de las denuncias de contradicción y solicitudes de sustitución de jurisprudencia conocimiento de los PC de forma sistematizada, ${ }^{22}$ esta herramienta es útil tanto para el personal que integra el órgano, como para el público

21 "ARTículo Único. Se reforman los artículos 5, 7, 13, fracciones VIII y IX; 19; 30 y 40 y se adicionan las fracciones X a XII al artículo 13, así como un segundo y tercer párrafo al artículo 44; y se derogan la fracción $\mathrm{V}$ del artículo 17; y los artículos 31, 32 y 33 del Acuerdo General 8/2015, del Pleno del Consejo de la Judicatura Federal, relativo a la integración y funcionamiento de los Plenos de Circuito, párrafo al artículo 44; y se derogan la fracción $\mathrm{V}$ del artículo 17; y los artículos 31, 32 y 33 del Acuerdo General 8/2015...".

22 Así se define en el propio manual, página 5. 
en general, quien tiene a su disposición la consulta de información inherente a estos órganos a través de la página web. ${ }^{23}$ * Protocolo que establece los lineamientos técnicos y formales para el uso y funcionamiento del sistema de plenos de circuito, cuyo objeto es establecer los lineamientos técnicos y formales que deben observar los usuarios para el uso y funcionamiento del sistema de $\mathrm{PC},{ }^{24}$ este instrumento está dirigido al personal del Poder Judicial quienes son los "usuarios" para efectos del mismo, ${ }^{25}$ su relevancia estriba en que las visitas de inspección a los PG se realiza a través del monitoreo a distancia del referido sistema electrónico.

* Acuerdo General 25/2013 del Pleno del Consejo de la Judicatura Federal que establece la implementación de libros electrónicos de registro para Plenos de Circuito. Se integra de 8 artículos y 3 transitorios, regula los libros electrónicos que los Plenos de Circuito están obligados a llevar como mecanismos de control de los asuntos, para la rendición de estadística y el desahogo de las visitas de inspección que se lleven a cabo, los apartados que deben contener y los lineamientos para el registro en cada uno de los apartados de los libros de control. ${ }^{26}$

Con relación a la jurisprudencia que emiten:

* Acuerdo General 19/2013 del Pleno de la Suprema Corte de Justicia de la Nación, difusión del Semanario Judicial de la

23 <www.cjf.gob.mx/plenoscircuito.htm>.

24 De acuerdo con el artículo 1 del ordenamiento.

25 En el protocolo se señala: "4. Son usuarios del sistema de Plenos de Circuito: I. El Magistrado Presidente del Pleno de Circuito. II. Los Magistrados Integrantes del Pleno de Circuito. III. Los Magistrados del Circuito. IV. Secretarios de acuerdos. V. La Visitaduría Judicial del Consejo de la Judicatura Federal. VI. El administrador: Las Direcciones Generales de Estadística Judicial y de Tecnologías de la Información".

26 En el artículo 1, así se dispone. 
Federación vía electrónica, a través de la página de Internet de ese alto tribunal. Se integra de 13 artículos y 7 transitorios, como su denominación lo indica, versa sobre la regulación de la publicación en el Semanario Judicial de la Federación de las tesis, jurisprudenciales y aisladas que emitan, entre otros entes, los PC, así como los votos, ejecutorias o de su parte considerativa y demás documentos que se ordene publicar o cuya difusión sea obligatoria.

* Acuerdo General 20/2013 del Pleno de la Suprema Corte de Justicia de la Nación, que establece las reglas para la elaboración, envío y publicación en el Semanario Judicial de la Federación y su Gaceta, de las tesis que emiten la Suprema Corte de Justicia de la Nación, los Plenos de Circuito y los Tribunales Colegiados de Circuito. Compuesto de 40 artículos y 4 transitorios, precisa los procedimientos y órganos competentes para la elaboración, envío y publicación de las tesis que emiten, en lo que interesa, los $\mathrm{PC}$, en la sección tercera regula las obligaciones del personal designado y otra dato interesante de este documento normativo es que prevé el recurso de inconformidad para el supuesto de que la Coordinación encargada se niegue a publicar un criterio. ${ }^{27}$

Acuerdos que deben comentarse:

* Acuerdo General 29/2013 del Pleno del Consejo de la Judicatura Federal, que adiciona un segundo párrafo al artículo 38 y otro diverso entre los párrafos primero y segundo del artículo 39 del Acuerdo General 7/2008, que regula la organización y funcionamiento de la Visitaduría Judicial del Consejo de la Judicatura Federal. Se conforma de artículo único y cuatro transitorios, en él se establece que la inspección ordinaria a los

27 Título Sexto. De los Recurso, artículo 40. 
PC se llevará a cabo a distancia, una vez al año y podrá durar hasta dos días.

* Acuerdo General 22/2013 del Pleno de la Suprema Corte de Justicia de la Nación, por el que se dispone el aplazamiento en el dictado de la resolución de las contradicciones de tesis del conocimiento de los PC, en las que se aborden los temas relativos al plazo de para promover demanda de amparo contra sentencias condenatorias que impongan pena de prisión, actos dentro del juicio penal que afecten ataques a la libertad persona y actos que implique ataques a la libertad fuera de procedimiento, dictados antes o con posterioridad a la entrada en vigor de la Ley de Amparo, publicada en el Diario Oficial de la Federación del dos de abril de dos mil trece, en vigor a partir del día tres siguiente. Se conforma del artículo único y dos transitorios, modificado el último de ellos mediante instrumento normativo de trece de enero de dos mil catorce.28

* Acuerdo General 11/2014 del Pleno de la Suprema Corte de Justicia de la Nación, por el que se dispone el aplazamiento en el dictado de la resolución de las contradicciones de tesis del conocimiento de los Plenos de Circuito, en las que se aborden los temas relativos a la fijación del alcance de lo dispuesto en el artículo 107, fracción V, de la Ley de Amparo, en espeć́fico si los pronunciamientos emitidos dentro del juicio sobre la personalidad de las partes, que no implican poner fin a éste, constituyen actos de imposible reparación. Contiene solo un artículo y dos transitorios.

Los dos últimos documentos reglamentarios son relevantes para sostener los postulados que enseguida se expresan relacionados con la efectividad de los Plenos de Circuito, pues las consideraciones

28 Por el que se dispone el aplazamiento en el dictado de la resolución de las contradicciones de tesis del conocimiento de los Plenos de Circuito y se conforma de un artículo y dos transitorios. 
que le dan lugar sugieren la posibilidad de aplazamiento de una resolución de contradicción de tesis, tomando como sustento la defensa de los derechos humanos conforme a lo dispuesto en el artículo $1^{\circ}$ constitucional, en aras del acceso efectivo a la justicia hasta en tanto resolviera la Suprema Corte a fin de evitar el dictado de sentencias contradictorias o contrarias al criterio fijado por dicho Tribunal terminal.

Otros instrumentos:

Criterios:

STGGNO/3645/2013, derivó de una consulta efectuada al Consejo de la Judicatura Federal y definió como debía ser la intervención de los Magistrados integrantes en la discusión de los asuntos, señalando la forma que el integrante del $\mathrm{PC}$ podía participar en las discusiones a partir del criterio sustentado por el órgano jurisdiccional que representare pero pudiendo emitir su voto en uso de su independencia judicial.

STCGNO/4729/2013, fijó que corresponde al Magistrado Presidente del PG continuar conociendo del trámite de los asuntos del mismo durante el periodo de transición de cambio de integración.

Circulares:

Circular 4/2013 PC, cuya finalidad fue establecer las medidas necesarias para la integración y funcionamiento de los de los PG en el 2014, por lo que reguló el nombramientos en los primeros días del presidente de tribunales a efecto de verificar el decanato.

Circular 9/2014-IV, surge con motivo de una consulta previa, determinó que a partir del uno de enero de dos mil catorce, el Pleno 
del Decimosexto Circuito dejará de ser mixto, para pasar a formar tres Plenos especializados (Administrativa, Civil y de Trabajo).

Circular 16/2014-I, surge con motivo de la consulta C/9212013IV, autorizada por la Comisión de Creación de Nuevos Órganos el veintinueve de noviembre de dos mil trece, determinó que a partir del uno de enero de dos mil catorce, el Pleno del Decimosexto Circuito dejaría de ser mixto, para pasar a formar tres Plenos especializados (Administrativa, Civil y de Trabajo)

\section{SOBRE SU ORGANIZACIÓN}

\section{INTEGRACIÓN}

Los PC pueden estar integrados por todos los magistrados adscritos a un Circuito cuando únicamente haya dos tribunales colegiados, ${ }^{29}$ en el supuesto de que existan más órganos colegiados se integrará por el magistrado elegido por el Pleno del Tribunal, el cual no podrá ser el Presidente del propio órgano jurisdiccional, salvo que el órgano jurisdiccional se encuentre integrado con dos secretarios de tribunal en funciones de magistrado de Circuito, en cuyo caso, el Presidente del Órgano Jurisdiccional sí integrará el Pleno, ${ }^{30}$ la renovación de integrantes se efectúa de forma anual, así que en realidad hay una especie de acuerdo interno en el que se asume una rotación, integra uno de los magistrados y el siguiente año el otro, así sucesivamente, esto porque además el acuerdo reglamentario prevé que no puede integrar el presidente del tribunal y tampoco

29 En los circuitos en los que solo existe un tribunal colegiado, no existe Pleno de Circuito, tal es el caso del trigésimo primer y trigésimo segundo circuitos, con sede en Campeche y Colima, información del Consejo de la Judicatura Federal: <http://www.cjf.gob.mx/DIrectorios/OJintcirc.aspx? cir=31>.

30 No puede dejarse de mencionar la antinomia que existe entre los artículos 40 y 5 del acuerdo reglamentario, pues el primero permite que el presidente del tribunal integré el Pleno de Circuito y el diverso no lo permite "en ningún caso". 
puede reelegirse a quien integró para el periodo inmediato posterior, salvo que se trate de una adscripción diversa, ${ }^{31}$ de manera que por exclusión solo queda un magistrado apto para conformar el PG. También debe mencionarse que el proceso de selección mutó desde su origen, pues conforme a la primer regulación, los presidentes de cada tribunal integraban el PC, sin embargo muchas fueron las críticas y las peticiones por parte de los magistrados en el sentido de variar esta situación, pues implicaba una carga laboral adicional que debía coordinarse con la presidencia del propio órgano colegiado, es decir, se tenía una triple labor: como magistrado del tribunal colegiado, como presidente de éste y como integrante del PC, finalmente tal solicitud se tomó en cuenta y se modificó para quedar en los términos precisados. ${ }^{32}$

Existen entonces integraciones de PG muy variadas en cuanto a su cualidad y cantidad, respecto del primero podemos clasificarlos en:

a) PC sin especialización, que se integran por magistrados de tribunales de diferentes materias - como es el supuesto del vigésimo segundo circuito, con residencia en Querétaro $^{-33}$ o mixtos (como el trigésimo circuito con residencia en Aguascalientes)

b) PG especializados, en las diversas materias en las que existen tribunales colegiados: civil, penal, administrativa y de trabajo, mención especial merece el Pleno de Circuito en Materia Administrativa, Especializado en Competencia Económica, Radiodifusión y Telecomunicaciones.

31 Acuerdo 8/2015 del Pleno del Consejo de la Judicatura Federal, artículos 5 y 16.

32 Ibidem, séptimo considerando.

33 En ese circuito existe un tribunal colegiado en materias penal y administrativa, uno más en materias administrativa y de trabajo y tres tribunales en materias administrativa y civil. 
En cuanto al número, los $\mathrm{PC}$ varían de estar integrados por una minoría de tres magistrados - por ejemplo el vigésimo séptimo circuito, con residencia en Cancún, Quintana Roo- hasta una cantidad de veintiún magistrados - como ocurre en el Pleno en materia Administrativa del Primer Circuito- ahora solo se precisa que esta diferencia conlleva a que la organización de cada Pleno de Circuito tenga necesidades distintas que van de lo simple a lo más complejo.

Algunas reglas adicionales respecto de la conformación de los $\mathrm{PC}$, son las siguientes:

a) Los tribunales colegiados auxiliares no componen ningún pleno. ${ }^{34}$

b) Los jueces de Distrito comisionados en funciones de magistrado de Circuito, integrarán plenos, no así los secretarios en funciones de magistrado de Circuito. ${ }^{35}$

c) Cuando en un Circuito se instale un nuevo tribunal, los magistrados que lo integren formarán parte del PC. ${ }^{36}$

Respecto de la distribución de funciones se puede decir que en el $\mathrm{PG}$ aparecen las siguientes:

a) Un presidente, seleccionado entre los tres magistrados de mayor antigüedad reciente y continua en el Circuito respectivo $^{37}$ - en el caso del Pleno de Circuito en Materia Administrativa, Especializado en Competencia Económica, Radiodifusión y Telecomunicaciones será la antigüedad como magistrado, con independencia de su adscripción y de la materia- durará un año en su cargo y no podrá ser reelecto para los dos periodos inmediatos posteriores,

34 Acuerdo 8/2015 del Pleno del Consejo de la Judicatura Federal, artículo 6.

35 Ibidem, artículo 7.

36 Ibidem, artículo 8.

37 Ibidem, artículo 11, primer párrafo. 
independientemente del tribunal colegiado al que se encuentre adscrito; ${ }^{38}$ será suplido por el magistrado decano que le siga en antigüedad en la integración del Pleno, sin que pueda ser designado Presidente para el período inmediato siguiente. ${ }^{39}$ Sus funciones esenciales son convocar y presidir las sesiones del Pleno y dictar los trámites que procedan en los asuntos de la Competencia del Pleno, hasta ponerlos en estado de resolución. ${ }^{40}$

b) Los magistrados integrantes, duran un año en su cargo y no pueden ser reelectos para el periodo inmediato posterior, salvo que se trate de una adscripción diversa, ${ }^{41}$ ya se mencionó su forma de selección y sus funciones más relevantes son asistir y participar con voz y voto a las sesiones del PC; presentar con oportunidad los proyectos de resolución a su cargo, solicitar el aplazamiento o retiro del o los asuntos, cuando así lo estimen pertinente. ${ }^{42}$

c) Secretario de Acuerdos, puede tratarse de una plaza ad hoc creada a partir de las modificaciones reglamentarias de diciembre de dos mil quince; sin que se dispusiera la forma de asignación del cargo; de manera que esto se llevó a cabo de diversas maneras -en algunos casos se realizó la selección a través de un examen, en otros mediante acuerdo entre los integrantes del PC, otros más por designación directa del Presidente- ${ }^{-}$en los supuestos en los que no existe tal nombramiento, el secretario será quien determine el presidente del PC, ${ }^{43}$ entre sus funciones destacan la de dar

38 Ibidem, artículo 11, segundo párrafo.

39 Ibidem, artículo 14.

40 Ibidem, artículo 13.

41 Ibidem, artículo 16.

42 Ibidem, artículo 17.

43 Ibidem, artículo 23. 
fe de todas las actuaciones, principalmente las sesiones, auxiliar a los magistrados, certificar los documentos emitidos por el PC y tramitar los expedientes de contradicciones de tesis y sustituciones de tesis. ${ }^{44}$

d) Personal administrativo, hay una ausencia normativa respecto de quienes llevaran a cabo las labores operativas del $\mathrm{PC}$, tales como la grabación de las sesiones, la notificación de las determinaciones y la recepción de las promociones, en lo fáctico esas faenas las realiza la plantilla del Presidente del PC, es el oficial de partes, el coordinador técnico y el actuario adscritos al tribunal que integra dicho presidente, quien asumen esa carga de trabajo.

\section{Asuntos de su competencia}

Los PG son competentes para:

a) Resolver las contradicciones de tesis de jurisprudencia sostenidas entre los tribunales colegiados del circuito correspondiente;

b) Denunciar ante el pleno o las salas de la Suprema Corte de Justicia, según la materia, las contradicciones de tesis de jurisprudencia en las que contienda alguna tesis sostenida por ese PC;

c) Resolver las solicitudes de sustitución de jurisprudencia que reciban por parte de los tribunales colegiados del circuito correspondiente o de sus integrantes. Aunque este no un mecanismo enteramente nuevo - anteriormente estaba prevista la modificación de jurisprudencia- de los elementos que vale la pena destacar son, primero, ni los ministros ni los magistrados pueden solicitar la sustitución de la jurisprudencia al órgano que

44 Ibidem, artículo 20. 
la emitió, eso tiene que hacerse por decisión de la mayoria; segundo, la solicitud siempre es de instancia inferior a superior, se elimina la posibilidad de auto solicitud de la sustitución; tercero, la sustitución es por votación calificada: dos terceras partes de los magistrados en Plenos, cuatro ministros en Salas y ocho ministros en el Pleno de la Suprema Corte de Fusticia de la Nación; ${ }^{45} \mathrm{y}$

d) Solicitar a la Suprema Corte de Justicia que inicie el procedimiento de declaratoria general de inconstitucionalidad cuando dentro de su circuito se haya emitido jurisprudencia derivada de amparos indirectos en revisión en la que se declare la inconstitucionalidad de una norma general.

Además, también conocen: ${ }^{46}$

e) De las excusas o impedimentos de los magistrados en asuntos competencia del Pleno;

f) De los avisos mediante los cuales se manifieste la falta justificada de sus integrantes; y

g) De las demás atribuciones que se le confieran en las disposiciones aplicables. En este rubro podría hablarse de decisiones como el returno y compensación de asuntos, alguna cuestión incidental, la solicitud a la Suprema Corte de Justicia para que conozca de alguna contradicción de tesis o inclusive el recurso de reclamación que se interponga contra algún auto de trámite. ${ }^{47}$

\section{Forma en que resuelven}

45 Mejía Garza, Raúl Manuel, "Jurisprudencia y declaratoria general de inconstitucionalidad” en Cossío Díaz José Ramón et. al (coords.) La Nueva Ley de Amparo, México, Porrúa, 2015, pp. 532 y 533.

46 Acuerdo 8/2015 del Pleno del Consejo de la Judicatura Federal, artículo 45.

47 En el Pleno en Materia Civil del Tercer Circuito se presentaron ambas situaciones en la contradicción de tesis 3/2016, se resolvió la reclamación 1/2016. 
La resolución de los asuntos conocimiento del Pleno de Circuito lleva el siguiente mecanismo:

a) Denuncia de la contradicción. Los sujetos legitimados -Procurador General de la República, los TC y sus integrantes, los Magistrados de Tribunal Unitario de Circuito, los Jueces de Distrito o las partes en los asuntos que las motivaron ${ }^{-48}$ presentan la denuncia de contradicción de tesis ante el presidente del PC, este integra el expediente solicitando a los órganos contendientes copia de las ejecutorias y la información sobre la vigencia del criterio, da aviso a la Suprema Corte de Justicia y turna el asunto para su resolución.

b) Proyecto. El magistrado ponente presenta el proyecto de resolución -dentro de los quince días hábiles siguientes a que se turnó el asunto- mediante el sistema electrónico que automáticamente lo distribuye a todos los magistrados del circuito a través de los correos electrónicos. ${ }^{49}$

c) Observaciones. Los magistrados integrantes del PC, cuentan con el término de diez días hábiles para formular las observaciones que estimen procedentes al proyecto de resolución correspondiente, las cuales, dentro de ese plazo se entregará al Presidente del Pleno y éste a su vez las hará llegar a los integrantes del PC para su conocimiento y discusión el día de la celebración de la sesión ordinaria siguiente, ${ }^{50}$ debe mencionarse que constituye una facultad potestativa la emisión de observaciones, de modo que válidamente pueden omitirse su presentación y realizarse en el momento de la sesión.

48 Conforme al artículo 227, fracción III de la Ley de Amparo.

49 Acuerdo 8/2015 del Pleno del Consejo de la Judicatura Federal, artículos 28 y 29.

50 Ibidem, artículo 30. 
d) Sesión. Los proyectos de resolución y las observaciones respectivas, se incluirán en la lista de asuntos a analizarse en sesión, previa convocatoria en la que se contiene la orden del día. ${ }^{51}$ La sesión se celebrará válidamente con la concurrencia de la mayoría de sus integrantes o todos ellos cuando se conforman por tres magistrados. ${ }^{52}$

e) Engrose y publicación de la tesis. El engrose y en su caso voto particular de la resolución emitida deberá realizarse dentro de los diez días hábiles siguientes al de la emisión del fallo del asunto. Por lo que ve al proyecto de tesis, una vez aprobado, se realiza el trámite para su publicación ${ }^{53}$ en el Semanario Judicial de la Federación.

\section{iv. Problemática}

\section{Dependencia operativa}

Se ha dicho ya que la complejidad de los PG varía de acuerdo con la situación en concreto de cada Circuito, sin embargo, en todos los supuestos carece de elementos para funcionar de forma autónoma respecto de dos rubros:

a) Requerimientos materiales. El PG comparte el domicilio oficial con el del tribunal de adscripción que corresponda a su presidente, en ese lugar las partes tramitan todo lo relacionado con las contradicciones y sustituciones de tesis,${ }^{54}$ esto implica un primer inconveniente, en la medida en que la presentación de promociones y notificación de acuerdos relativos a los PG no tienen un espacio exclusivo

51 Ibidem, artículos 36 y 37.

52 Ibidem, artículo 39.

53 Ibidem, artículo 50.

54 Ibidem, artículo 23. 
lo que conlleva a la confusión no solo para el público, sino para los operadores judiciales que desconocen en qué libros registrar los ocursos y comunicados, o la forma en que han de notificar en los procedimientos de contradicción de tesis o sustitución. Por otra parte, las sesiones de los PC se verifican en los lugares o espacios asignados por el Consejo, los cuales se ubicarán en la localidad del Circuito en la que residan el mayor número de TC, aun cuando no coincida con el domicilio oficial, este aspecto transciende sobre todo en los circuitos en los que hay tribunales en distintas sedes ${ }^{55}$ que pueden estar lejanas por distancias considerables como es el caso del Octavo y del Decimonoveno Circuito, ${ }^{56}$ ya que implican traslados de más de tres horas, ${ }^{57}$ con todos los inconvenientes y costos que ello implica, sin que pase desapercibido que la sesión se puede llevar a cabo mediante el sistema de videoconferencia; ${ }^{58}$ sin embargo, este mecanismo requiere de una infraestructura similar a la del PC, es decir, se requiere instrumentar dos instalaciones.

b) Elemento humano. La falta de personal ad hoc de los PC es una problemática para todos los que participan en ellos, comenzando por los titulares, antes se mencionó que inicialmente eran los presidentes de cada TG quienes

55 Es el supuesto del Segundo Circuito con residencias en Toluca, Naucalpan de Juárez y Ciudad Nezahualcóyotl, Estado De México.

56 Con residencia el primero, en Coahuila y sedes en Saltillo y Torreón; el segundo relativo a Tamaulipas con sedes en Ciudad Victoria y Reynosa.

57 De Ciudad Victoria a Reynosa el traslado en automóvil se calcula en 3 horas y 46 minutos y de Saltillo a Torreón: 2 horas y 57 minutos: <http://www. mexicodistancia.com/distance/18005115-18004396> y <http://www.mexicodistancia.com/distance/18010263-18008074>.

58 De acuerdo con el artículo 44 del Acuerdo 8/2015 del Pleno del Consejo de la Judicatura Federal. 
integraban el PC, afortunadamente hoy en día se eliminó tal práctica, pero lo cierto es que el magistrado integrante tiene que lidiar con las labores del PG y las de su propio órgano lo cual no resulta una tarea sencilla, sobre todo si se tiene un verdadero compromiso en tales funciones, pues debe coordinar no solo los horarios de sesiones, sino las labores que pueden coincidir, pienses por ejemplo cuando se presenta una queja de las previstas en la fracción I, inciso b) del artículo 97 de la Ley de Amparo, cuya resolución es inmediata -48 horas conforme al artículo 101 de la Ley de Amparo- en la época en que tiene sesión en el PC, es evidente que la atención de los magistrados integrantes se distrae obligadamente por situaciones inherentes a su cargo como integrante del TG -ya algún autor estima como notoria la ignorancia e incapacidad de muchos de los Magistrados al resolver las contradicciones de tesis ${ }^{-59}$ lo que se traduce en un deficiente rol como integrante del PC. La situación del resto del personal que debe participar en el funcionamiento del PC no es distinta - salvo el caso del Secretario de Acuerdos cuando existe plaza autorizada exprofeso para tal cargo $^{-}$el oficial de partes quien recepciona a las promociones y oficios del $\mathrm{PG}$, el coordinador técnico que efectúa la videograbación de las sesiones y el actuario judicial a quien corresponde las notificaciones necesarias que deriven de la tramitación de los asuntos conocimiento del PC, son personal de la plantilla del presidente del PG que debe realizar las labores extraordinarias referidas, sin descuidar las propias de su función. Puede añadirse la ausencia de auxiliares administrativos que apoyen en las faenas que ordinariamente

59 Chávez Castillo Raúl, La nueva Ley de Amparo comentada, 6a. ed. México, Porrúa, 2014, pp. 672 y 673. 
llevan a cabo y que en caso de no contar con ese apoyo, el secretario de acuerdos del PG es quien las realiza, tales como la transcripción de antecedentes o fotocopiado de los mismos, la integración material de los expedientes, expedición de caratulas, su costura, etcétera, e inclusive el registro en el sistema electrónico de todas las actuaciones, siendo este último de gran relevancia pues como ya quedó de manifiesto, las visitas de inspección se realizan por ese medio.

\section{Plazo de Resolución de las contradicciones}

Otro aspecto que merece atención es el término para resolver las contradicciones de tesis, el acuerdo reglamentario regula que el proyecto de resolución deberá formularse dentro de los quince días hábiles siguientes a que se turnó el asunto, en sus orígenes esta disposición no existía, de modo que cada PG fijaba un plazo de resolución, ${ }^{60}$ como excepción a esa regla general se encuentra el hecho de que por causa justificada el propio PC o el presidente determinen un plazo mayor, salvedad que se presta para varias trampas, la primera es que en las reglas básicas -especie de reglamento interior que el PG emite en la primera sesión conforme al artículo 37 de acuerdo reglamentario vigente- ${ }^{-}$se convenga una ampliación del término de resolución; sin afán de justificar este proceder irregular, lo cierto es que el plazo fijado es demasiado corto, evidentemente su finalidad es la solución pronta de las contradicciones de tesis en aras de seguridad jurídica, así el plazo de incertidumbre sobre cuál es el criterio imperante en un circuito debe ser el menor; sin embargo, debe tenerse en cuenta que la solución de una contradicción de tesis no es tarea sencilla, simplemente si se parte de la noción de que sobre un mismo aspecto jurídico se emitieron dos posturas debida-

60 En el caso del Pleno en Materia Civil del Tercer Circuito, las reglas básicas fijaron un plazo de tres meses acorde a la Ley de Amparo. 
mente razonadas en sentido contrario, lo que implica por sí un caso difícil. Además, porque la solución que brinde el PG constituirá jurisprudencia obligatoria, de modo que tendrá un impacto relevante que requiere de un análisis minucioso que para ser resuelto en tres semanas requeriría de la atención exclusiva y tal vez ni siquiera en ese supuesto sería suficiente. Por otra parte, se tiene que los PC han llegado a concluir que para la solución de la contradicción de tesis requieren esperar a que la Suprema Corte de Justicia de la Nación resuelva determinado asunto, práctica que no tiene sustento alguno y es seriamente criticable, pues los fines de los PC son, precisamente, el fortalecimiento de los Tribunales Colegiados de Circuito y el reconocimiento de sus integrantes como conformadores efectivos de los criterios de interpretación de la legalidad; agilizar la solución de tales controversias en aras de la seguridad jurídica y la evidente tendencia a que la Suprema Corte de Justicia de la Nación se ocupe de aquellas cuestiones de transcendencia superior; propósitos que no se conformarían postergando la solución de las contradicciones de tesis y además atentan gravemente contra la autonomía de decisión del PG, aspecto que enseguida se analizara en particular.

\section{Autonomía de criterio}

La crítica a la toma de decisión en el PG tiene dos vertientes, una vinculada con la independencia del voto que emiten sus integrantes de forma individual y otra más con relación a la autonomía del criterio del PG frente a las decisiones de la Suprema Corte, para arribar al estudio del primer aspecto resulta conveniente realizar una narración sucinta de lo ocurrido a partir del origen de los PC:

El artículo 17, fracción V, del acuerdo 14/2013 del Pleno del Consejo de la Judicatura Federal establecía la facultad de los magistrados integrantes para participar en la discusión de las contradicciones de tesis, a partir del criterio adoptado por el tribunal colegiado que representaran, cuando el órgano citado no se hubiera 
pronunciado sobre el problema jurídico a resolver, el TC en formal sesión debía fijar el criterio indicado, para que su magistrado representante lo planteara ante el PC. Evidentemente esta disposición causó controversia entre los magistrados integrantes del PC de modo que en atención a la consulta efectuada al respecto se emitió el criterio STCGNO/3645/2013, en el que se precisó que el magistrado integrante del PC, debía iniciar su participación en las discusiones correspondientes, a partir del criterio sustentado por el órgano jurisdiccional que representara; sin embargo, su voto lo emitiría en uso de su independencia judicial, resultado del análisis y valoración de los argumentos vertidos durante el debate generado con motivo de la contradicción de tesis.

Esa normativa se abrogó y entro en vigor diversa -acuerdo 11/2014- que estableció en el mismo artículo y fracción, que el magistrado integrante debía hacer del conocimiento del PG el criterio adoptado por el tribunal colegiado que representara, al inicio de la discusión de las contradicciones de tesis, previa sesión en el supuesto de que no existiera criterio del TG. Tal disposición fue reiterada en el acuerdo 8/2015 del Pleno de Consejo de la Judicatura Federal, de forma idéntica y adicionalmente reguló un mecanismo mediante el cual se asentaba el sentido del voto del magistrado integrante mediante el sistema electrónico, de forma previa a la sesión del asunto y el presidente debía certificar la cantidad de votos y su sentido, ${ }^{61}$ de manera que en esa época el criterio del magistrado integrante además de anticipado al momento de la sesión, carecía de cualquier relevancia, pues la decisión mayoritaria del tribunal era el factor a tomar en cuenta y la sesión de las contradicciones de tesis se volvió una asunto de suma de votos, pues solo se exponían y contabilizaban éstos, pero en realidad no había aquel debate que procurara poder convencer al disidente o inclusive de inclinar la balanza hacía la postura de minoría.

61 En los artículos del 30 al 33. 
Afortunadamente esa forma de resolver se modificó a través del acuerdo 52/2015 del Pleno del Consejo de la Judicatura Federal en el que se consideró que:

a) La decisión del magistrado integrante del PC goza de autonomía respecto del criterio del tribunal que integra, lo cual tiene un impacto mayor, porque puede suceder que su postura sea la de minoría dentro del TC, pienses por ejemplo que sobre el tema que se resuelve ha votado en contra.

b) La resolución de las contradicciones de tesis corresponde al PG no así a los TC, se trata de la decisión un órgano distinto, diferenciado que puede tener una posición propia, ya apoyando algunas de las posturas que contienden o bien una diversa que surja del planteamiento de la contradicción de tesis, ${ }^{62}$ pues fijar el criterio de uniformidad en la interpretación que resuelve una contradicción de tesis supone determinar, en abstracto, cuál de los criterios seguidos en las ejecutorias que compiten es el correcto, razonamiento que no se realiza para confrontarla con los hechos de un caso concreto, sino para comparar o confrontar dos abstracciones, tesis o criterios jurídicos, de manera que la respuesta parte desde una perspectiva absolutamente teórica desprovista de la realidad, de la cual las ejecutorias partieron y pretendieron resolver. ${ }^{63}$

Esta forma de resolver por supuesto abona a la autonomía de decisión de los integrantes del PG quienes son responsables, ahora sí, de fijar la jurisprudencia local obligatoria, sin embargo, no puede perderse de vista que el sistema anterior buscaba evitar que el

62 Así lo establece el artículo 226 de la Ley de Amparo.

63 Quijano Villanueva, Guadalupe Eugenia, Análisis Crítico de la furisprudencia en México (Casos de reiteración y por contradicción de tesis), México, Porrúa, 201 1, p. 240, 247 y 248. 
criterio de minoría de un circuito se convirtiera en el de mayoría del PC o viceversa, con el cambio de integración; se explica, como cada año se rota a los magistrados integrantes, es posible que una misma controversia se estudie por dos PG distintos en cuanto a su conformación y que la decisión en ambos casos sea diversa, lo cual por supuesto no favorecería a dotar de certidumbre al foro jurídico pues determinado criterio sólo se encontraría vigente mientras se tiene una nueva integración del $\mathrm{PC}$, situación que aunque suena un tanto anómala y pudiera estimarse improbable, no lo es, esto, porque no hay que olvidar que conciliar posturas no es una tarea simple y más cuando puede tratase de tantas y variadas -véase el ejemplo que la Suprema Corte de Justicia integrada por once ministros que en ocasiones cada uno emite voto concurrente ${ }^{-64}$ y si a este se añade la personalidad de cada magistrado y los egos que pueden encontrarse lastimados, en realidad la fijación de la jurisprudencia puede convertirse en una batalla recurrente que deriva en un cambiante criterio obligatorio.

Por otra parte, es también cuestionable que las determinaciones de los PC constituyan una interpretación especializada e inédita del sistema jurídico local, en la medida en que en muchas ocasiones resultan una verdadera reiteración de lo dicho por la Suprema Corte de Justicia o una mescolanza de varios criterios jurisprudenciales -ya se ha dicho que algunos supuestos se pretende esperar a que ese tribunal resuelva determinado punto a debate para poder resolverlo- es innegable que la jurisprudencia del máximo tribunal del país además de obligatoria es apta para orientar casos análogos, pero debe destacarse que no toda resolución que dicta nuestro más Alto Tribunal es propiamente una sentencia constitucional, ya que también actúa como tribunal de legalidad al resolver las contradicciones de criterios de los TC o de las propias Salas de la Suprema

64 Como ocurrió al resolver la contradicción de tesis 293/2011. 
Corte, precisamente con la finalidad de unificar la jurisprudencia, ${ }^{65}$ por lo cual no es indefectible seguir uno de sus precedentes, mucho menos implica la imposibilidad de válidamente llegar a una conclusión diversa, debidamente razonada, pues incluso la misma corte llega a cambiar su criterio cuando existen argumento válidos; además, porque la jurisprudencia juega un papel importante en la evolución jurídica, en tanto que impide que el contenido normativo de las leyes permanezca estático ${ }^{66}$ de ahí lo válido y necesario de un cambio de criterio.

\section{4. ¿Y LA CONVENCIONALIDAD DE LA JURISPRUDENCIA?}

Hablando de la jurisprudencia y la autonomía del criterio de unificación resulta obligado considerar qué ocurre cuando un criterio de la Suprema Corte de Justicia se plantea inconvencional y el PG tiene que resolver una contradicción de tesis sobre el mismo tema que trata, cierto es que el Pleno de la Suprema Corte de Justicia de la Nación, por mayoría, ${ }^{67}$ estableció en la CT 299/2013 que la jurisprudencia emitida por dicha Corte no puede ser sometida a un control de convencionalidad por cualquier órgano jurisdiccional de menor jerarquía, ${ }^{68}$ sin embargo, tal decisión es contraria a la obligación constitucional de que todas las autoridades, en el ámbito

${ }^{65}$ Ferrer Mac-Gregor, Eduardo, Panorámica del Derecho procesal constitucional y convencional, 2da. reimp. México, Universidad Nacional Autónoma de México Instituto de Investigaciones Jurídicas Marcial Pons, 2017, p. 217.

${ }^{66}$ De Silva, Carlos, "La jurisprudencia, interpretación y creación del derecho" en Vázquez, Rodolfo (comp.) Interpretación jurídica y decisión judicial, 5ta., reimp., México, Fontamara, 2008, p. 151.

67 De siete votos a favor.

${ }^{68}$ En la tesis de jurisprudencia P./J. 64/2014 (10a.) publicada en el Semanario Judicial de la Federación del viernes 12 de diciembre de 2014 a las 9:35 horas y en la Gaceta del Semanario Judicial de la Federación, Décima Época, Libro 13, Tomo I, diciembre de 2014, página 8, con el título y subtítulo: "JURISPRUDENGia DE LA SUPREMA CORTE DE JUSTICIA DE LA NACIÓN. NO ES SUSCEPTIBLE DE SOMETERSE A 
de sus competencias, tienen la obligación de promover, respetar, proteger y garantizar los derechos humanos de conformidad con los principios de universalidad, interdependencia, indivisibilidad y progresividad. Además, el Alto Tribunal se aparta de propia su línea discusiva en la materia, ${ }^{69}$ aquí las razones por las que no se comparte tal postura:

a) La jurisprudencia es derecho normativo, se integra por un conjunto de precedentes que establecieron normas

GONTROL DE GONSTITUCIONALIDAD Y/O GONVENGIONALIDAD EX OFFICIO POR ÓRGANOS JURISDICGIONALES DE MENOR JERARQUÍA".

69 Al resolver la CT 259/2011, la Primera Sala sostuvo: “[...] En virtud del reformado texto del artículo $1^{\circ}$. Constitucional, se da otro tipo de control, ya que se estableció que todas las autoridades del Estado mexicano tienen obligación de respetar, proteger y garantizar los derechos humanos reconocidos en la Constitución y en los tratados internacionales de los que el propio Estado mexicano es parte, lo que también comprende el control de convencionalidad. Por tanto, se concluye que en el sistema jurídico mexicano actual, los jueces nacionales tanto federales como del orden común, están facultados para emitir pronunciamiento en respeto y garantía de los derechos humanos reconocidos por la Constitución Federal y por los tratados internacionales...". Mientras que la Segunda Sala, en la jurisprudencia de rubro: "CONTROL DE CONSTITUCIONALIDAD Y CONVENCIONALIDAD. CONDICIONES PARA SU EJERCICIO OFICIOSO POR LOS ÓRGANOS JURISDICGIONALES FEDERALES", estableció que: “... Las normas relativas a los derechos humanos se interpretarán de conformidad con la propia Constitución y con los tratados internacionales de la materia, favoreciendo en todo tiempo a las personas la protección más amplia, de donde deriva que los tribunales federales, en los asuntos de su competencia, deben realizar el estudio y análisis ex officio sobre la constitucionalidad y convencionalidad de las normas aplicadas en el procedimiento, o en la sentencia o laudo que ponga fin al juicio. Ahora, esta obligación se actualiza únicamente cuando el órgano jurisdiccional advierta que una norma contraviene derechos humanos contenidos en la Constitución Federal o en los tratados internacionales de los que el Estado Mexicano sea parte, aun cuando no haya sido impugnada, porque con su ejercicio oficioso se garantiza la prevalencia de los derechos humanos frente a las normas ordinarias que los contravengan". Bolaños Linares Rigel, Tutela EFICAZ de LOS DEREChOs Humanos E INCONVENCIONALIDAD DE LA JURisprudencia con un enfoque de derecho laboral burocrático, México, Porrúa, 2015, pp.19,20 y 21. 
particulares y que, por ello fueron creadores de derecho, ella también lo es, ${ }^{70}$ precisamente a partir de los criterios jurisprudenciales que se le atribuye un significado a algún enunciado normativo la mayoría de las veces tienen el objetivo de asignar el significado que ante un caso concreto tiene cierto enunciado normativo, pero también en otros casos, tales ejercicios de asignación de significado se plantean en abstracto, es decir, se busca determinar cuál es el significado normativo de un enunciado normativo con independencia de cualquier caso concreto, ${ }^{71}$ como ocurre al resolver una contradicción de tesis que ya se ha dicho es un ejercicio que no atañe a la solución de un caso particular, sino la fijación de un criterio general y de observancia obligatoria, como la norma. Aceptar que la interpretación judicial es normativa no implica justificar una total anarquía dentro del orden jurídico, tampoco que necesariamente deba ser arbitraria en el sentido de contrariar deliberadamente la razonabilidad de un sistema normativo, ${ }^{72}$ pero reconocer su naturaleza permite entender la importancia de su modificabilidad y posible inaplicación cuando trasgrede derechos humanos y el principio pro persona, esto se verá enseguida.

b) Respeto al derecho pro persona. La Constitución Federal establece como obligación de todas las autoridades el respeto de los derechos humanos reconocidos en la propia norma máxima y los tratados internaciones suscritos por el Estado mexicano, atendiendo al principio pro persona, de manera que no existe una limitación en cuanto a qué

70 De Silva, Carlos, "La jurisprudencia, interpretación y...”, cit., p. 151.

71 Cossío Díaz, José Ramón y Lara Chagoyán, Roberto, ¿Qué hacer con la jurisprudencia que viola derechos humanos?, "Revista del centro de estudios constitucionales", Suprema Corte de Justicia de la Nación, p. 8.

72 De Silva, Carlos, "La jurisprudencia, interpretación y...", cit., p. 151. 
autoridad debe darle cumplimiento, se entenderían incluidos por supuesto los PC, al respecto el ministro Silva Meza sostiene que la reforma constitucional suministra a los jueces las herramientas suficientes para que la impartición de justicia sea democrática, en el sentido de que los jueces, hoy, tienen la obligación de resolver los asuntos favoreciendo a las personas la protección más amplia, lo que significa que puede haber más y mejores derechos que los que la Constitución y la jurisprudencia hasta ahora han reconocido; de manera que el juez tiene el deber de aplicar en sus decisiones los derechos humanos (nacionales e internacionales) que resulten más vigorosos para la defensa de las personas y comprende la multiplicación de órganos y deberes de protección, ${ }^{73}$ donde se incluye a los PC como juzgadores y órganos terminales de decisión del criterio local. El principio pro persona tampoco se encuentra dirigido a algún tipo de ley, norma, decreto, acto administrativo o instancia federal-estatal determinadas, por lo que se asume que si la doctrina jurisprudencial fijada por la Suprema Corte de Justicia tiene la calidad de obligatoria, puede ser sometida al escrutinio de convencionalidad a la luz del referido principio pro homine. El ministro Cossío Díaz plantea el cuestionamiento de ¿Por qué la Suprema Corte podría escapar de ese control? La única respuesta posible es que su jurisprudencia sea infalible, afirmación que carece de cualquier valide $z^{74}$ y evidentemente incierta, baste tener en cuenta que la propia Corte modifica sus criterios jurisprudenciales con base en una "nueva reflexión"

73 Silva Meza Juan N. y Silva García Fernando, Derechos Fundamentales Bases para la reconstrucción de la jurisprudencia mexicana, México, 2013, 2da ed. Ed. Porrúa, p. 241,242 y 713

74 Cossío Díaz, José Ramón y Lara Chagoyán, Roberto, “¿Qué hacer con la jurisprudencia...", cit., pp. 11 y 12 
que en muchos casos obedece precisamente a la finalidad de adecuar la interpretación de la norma con los estándares convencionales actuales.

c) Autonomía de decisión del PG. Ya se ha dicho que los PG fueron dotados constitucionalmente de independencia para determinar la jurisprudencia obligatoria local, pero como podría materializarse si se le coarta el derecho de decidir que un criterio de la Suprema Corte de Justicia que contraviene el orden convencional es inaplicable, lo cual además le impide resolver conforme a un argumento racional:

Si a un órgano no le está permitido justificar su decisión a la luz de algún derecho y, en consecuencia, no le está permitido inaplicar cualquier norma (de fuente legislativa o jurisprudencial) por considerarla inconstitucional o inconvencional, entonces, a falta de una buena razón que justifique tal restricción, se estaría asumiendo, de antemano, la incapacidad de tal órgano para argumentar correctamente sobre lo que exigen los derechos. ${ }^{75}$

\section{v. Conclusión y aportaciones}

La jurisprudencia procura elaborar propuestas de solución que se ajusten al derecho vigente, ${ }^{76}$ así, cuando coexisten posturas opuestas sobre temas estructurales, se ponen en riesgo de relativizar el valor que tienen dentro del Estado constitucional, con la consecuente probabilidad de una aplicación judicial arbitraria del derecho, ${ }^{77}$ por

75 Cossío Díaz, José Ramón y Lara Chagoyán, Roberto, “¿Qué hacer con la jurisprudencia...", cit., p.10.

76 Larenz, Karl, Metodología de la Ciencia del Derecho, 2da. ed., Barcelona, España, 2001 p. 229.

77 Silva Meza, Juan N. y Silva García, Fernando, Derechos Fundamentales Bases para la reconstrucción de la jurisprudencia mexicana, 2da ed. México, Porrúa, 2013, p. 713. 
ello a partir de las reformas constitucionales se instituye un nuevo órgano de solución de contradicciones de tesis, los PC, que procuran .la unificación de un criterio local necesario para el sistema mexicano pues cada región del país presenta problemáticas propias que conocen los operadores de derecho en contacto día a día con ellas, siendo los más capacitados para darles solución, sin embargo, la regulación y estructura de los PC requiere de transformaciones a fin de que cumplir con los fines para los cuales fueron creados por lo que se propone:

Primero. Que la regulación esencial del PC deje de ser reglamentaria y se prevea en una norma, como podría ser la Ley Orgánica del Poder Judicial de la Federación o la Ley de Amparo, con lo cual se limita su modificación instantánea -ya que evidentemente la reforma legislativa implica un proceso más formal que la mutación de los acuerdos expedidos por el Consejo de la Judicatura Federalconsolidando la estructura de los PC.

Segundo. Establecer la posibilidad de que se denuncia la contradicción de tesis de un asunto pendiente de resolución y se aplique al mismo la jurisprudencia que se imponga como obligatoria, esto sin transigir la cosa juzgada en aquellos casos que estuviese resueltos, con lo cual se evitaría que aun advirtiéndose la divergencia de criterios, se aplique uno de ellos en franca contravención al principio de seguridad jurídica.

Tercero. Ampliar el plazo de resolución de las contradicciones de tesis a tres meses -homologándose a lo establecido en la Ley de Amparo- previéndose que la modificación de dicho término solo puede ampliarse por causas extraordinarias debidamente justificadas y previstas en la norma.

Cuarto. Se limite la existencia de un solo PG en cada región, integrado por magistrados del circuito respectivo dedicados exprofeso a tal función, este cambio favorecería la debida conformación del criterio jurisprudencial unificador porque sería el único quehacer de los titulares, además porque no estarían ligados al criterio de 
algún TC, así se uniformaría y reduciría el número de integrantes del PC sin dejar de aprovechar la experiencia de los magistrados de circuito; además, la integración del PG se conservaría al menos tres años para evitar las transiciones cíclicas tan breves que existen y provocan una inestabilidad en el desarrollo de las funciones del PG.

Quinto. Dotar al PG de personal ad hoc para las funciones que realiza, un Secretario de Acuerdos, al menos un auxiliar administrativo, un oficial de partes y un actuario. Con ello se dotaría de autonomía operativa al PG y de consiguiente la integración de expediente y publicitación de los criterios de jurisprudencia que emitan podrá tener mayor efectividad.

Sexto. El PG debe tener la posibilidad de inaplicar un criterio jurisprudencial de la Suprema Corte que sea inconvencional y decidir de manera razonada cual es la jurisprudencia obligatoria en el circuito.

Vi. Fuentes de consulta

LIBROS

Alvarado Esquivel, Miguel de Jesús, "La jurisprudencia por resolución de contradicciones de tesis de la nueva Ley de Amparo. Criticas para su eliminación", en Ferrer Mac-Gregor, Eduardo y Herrera García, Alfonso (coords.) El fuicio de Amparo en el centenario de la Constitución Mexicana de 1917 pasado, presente y futuro t. II, México, Universidad Nacional Autónoma de México, Instituto de Investigaciones Jurídicas, 2017.

Bolaños Linares, Rigel, Tutela eficaz de los derechos humanos e inconvencionalidad de la jurisprudencia con un enfoque de derecho laboral burocrático, 2015, Porrúa, México.

Bravo Peralta, Martín Virgilio, Método del caso jurisprudencial interpretación, argumentación y jurisprudencia, $2^{\mathrm{a}}$. reimp., Ciudad de México, Porrúa, 2016. 
Brewer-Carías, Allan R., El Proceso de Amparo en el Derecho Constitucional Comparado de América Latina, México, Porrúa, 2016.

Chávez Castillo, Raúl, La nueva Ley de Amparo comentada, 6a. ed. México, Porrúa, 2014.

De Silva, Carlos, "La jurisprudencia, interpretación y creación del derecho" en Vázquez, Rodolfo (comp.) Interpretación jurídica y decisión judicial, 5ta., reimp., México, Fontamara, 2008.

Ferrer Mac-Gregor, Eduardo, Panorámica del Derecho procesal constitucional y convencional, 2da. Reimp. México, Universidad Nacional Autónoma de México Instituto de Investigaciones Jurídicas Marcial Pons, 2017.

— y Sánchez Gil, Rubén, El Nuevo fuicio de Amparo. Guía de la reforma constitucional y la nueva Ley de Amparo, 4ta ed, México, Porrúa, 2013.

Hitters, Juan Carlos, Control de Convencionalidad Adelantos y Retrocesos, Ed. Porrúa.

Mejía Garza, Raúl Manuel, "Jurisprudencia y declaratoria general de inconstitucionalidad" en Cossío Díaz José Ramón et. al (coords.) $L a$ Nueva Ley de Amparo, México, Porrúa, 2015.

Qujano Villanueva, Guadalupe Eugenia, Análisis Crítico de la Furisprudencia en México (Casos de reiteración y por contradicción de tesis), México, Porrúa, 2011.

Larenz Karl, Metodología de la Ciencia del Derecho, 2da. ed., Barcelona, España, 2001.

Silva Meza, Juan N. y SILVA GARCÍA Fernando Derechos Fundamentales Bases para la reconstrucción de la jurisprudencia mexicana, 2da ed. México, Porrúa, 2013.

SOSA ORTIZ Alejandro, La jurisprudencia en la nueva ley de amparo. $2^{\mathrm{a}}$ ed, México, Porrúa, 2017.

\section{LEYES}

Constitución Política de los Estados Unidos Mexicanos

Ley Orgánica del Poder Judicial de la Federación 
Ley de Amparo

Acuerdo General 14/2013 del Pleno del Consejo de la Judicatura Federal Acuerdo General 11/2014 del Pleno del Consejo de la Judicatura Federal Acuerdo General 8/2015 del Pleno del Consejo de la Judicatura Federal Acuerdo General 52/2015 CJF

Acuerdo General 25/2013 del Pleno del Consejo de la Judicatura Federal Acuerdo General 19/2013 del Pleno de la Suprema Corte de Justicia de la Nación

Acuerdo General 20/2013 del Pleno de la Suprema Corte de Justicia de la Nación

Acuerdo General 29/2013 del Pleno del Consejo de la Judicatura Federal Acuerdo General 22/2013 del Pleno de la Suprema Corte de Justicia de la Nación

Acuerdo General 11/2014 del Pleno de la Suprema Corte de Justicia de la Nación

Circular 4/2013 PG

Circular 9/2014-IV

Circular 16/2014-I

Criterio STCGNO/3645/2013

Criterio STCGNO/4729/2013

Manual de usuario del Sistema de Plenos de Circuito

Plenos de Circuito sin especialización

Plenos de Circuito especializados

Protocolo que establece los lineamientos técnicos y formales para el uso y funcionamiento del sistema de plenos de circuito

REVISTA

Cossío Días, José Ramón y LaRa Chagoyán, Roberto, ¿Qué hacer con la jurisprudencia que viola derechos humanos?, "Revista del centro de estudios constitucionales", Suprema Corte de Justicia de la Nación. 
Rodríguez, magally, "Los Plenos de Circuito deberán respetar, por encima de todo, los derechos humanos: Ministro Silva Meza", Compromiso, Órgano informativo del Poder Judicial de la Federación, México, Junio 2013, año 12/No. 144- junio de 2013.

\section{SiTIOS DE INTERNET}

$<$ www.cjf.gob.mx/plenoscircuito.htm>.

$<$ https://agendamagna.wordpress.com/2013/05/26/unificacion-de-la -jurisprudencia/>.

$<$ www.gob.gba.gov.ar/legislacion/legislacion/l-5827.html>.

$<$ www.cjf.gob.mx/DIrectorios/OJintcirc.aspx?cir=31>.

<www.mexicodistancia.com/distance/18005115-18004396>

<www.mexicodistancia.com/distance/18010263-18008074>. 